\title{
A necropsy study of pulmonary emphysema in Glasgow
}

\author{
G. HEFIN ROBERTS and K. W. M. SCOT T ${ }^{1}$ \\ Department of Pathology, Southern General Hospital, Glasgow, S.W.1
}

The incidence of pulmonary emphysema in a series of 50 necropsies on male subjects in Glasgow has been investigated. Emphysema was present in 37 lungs (74\%) and found in more than trace amounts in 32 lungs (64\%). These results are similar to those previously reported from London, Edinburgh, and Cardiff but emphysema in younger men appears to be more severe in Glasgow than in these other cities.

Centrilobular emphysema was the commonest variety, found in 36 of the 50 lungs $(72 \%)$; it was the only or predominant type in $17(34 \%)$. Panlobular emphysema was found in 25 lungs $(50 \%)$, but only in $5(10 \%)$ was this the predominant or the only variety. In 15 cases $(30 \%)$, significant amounts of both centrilobular and panlobular emphysema were present.

Three methods were used to measure emphysema, including the recently introduced method which compares the severity of emphysma on paper-mounted large sections with standard charts arbitrarily graded according to severity. The method of scoring is quick and gave results comparable to those using Heard's method on the barium impregnated slice. It has the added advantage that paper-mounted sections, unlike barium-impregnated slices, are easily stored and thus provide a permanent record.

\section{INTRODUCTION AND AIMS}

Geographical studies have shown that emphysema like chronic bronchitis is commoner in the United Kingdom than in certain other countries (Gough, Ryder, Otto, and Heller, 1967; Heard, 1969). Studies from different regions within the United Kingdom have been few. Heard and his colleagues have collected data from necropsies in London and Edinburgh (Heard and Izukawa, 1964; Heard and Hossain, 1970); the incidence of emphysema was similar in the two cities. Gough et al. (1967) found that the incidence of emphysema in Cardiff was approximately three times greater than in Erlangen (Germany) but close to that found in London.

In Glasgow the mortality from 'bronchitis and emphysema' is high. The death rate per million of the population in 1969 (856) was exceeded only by deaths due to malignant disease, ischaemic heart disease, and cerebrovascular disease (M.O.H. Report, 1969). The purpose of this paper is to provide information on the incidence and types of emphysema in a series of necropsies on male subjects in Glasgow.

Recently a new method of measuring emphysema has been devised by Thurlbeck and his colleagues

1Present address: Department of Pathology, University of Sheffield
(1970). In this method paper-mounted large sections (Gough and Wentworth, 1960) are compared with a set of photographed paper-mounted sections which have been graded according to the severity of the emphysema. This method has been used in the present study as we.l as the better known methods of Heard and Izukawa (1964) and the point-counting technique (Dunnill, 1962; Hicken, Heath, and Brewer, 1966).

\section{MATERIALS AND METHODS}

Fifty left lungs collected from every fourth male necropsy between April 1970 and March 1971 were examined for emphysema using three methods.

Following distension and fixation with $10 \%$ buffered formol-saline, an $8 \mathrm{~mm}$ mid-sagittal slice of lung was impregnated with barium sulphate (Heard, 1958). The lung slice was examined under water with the naked eye and with a hand lens. The amount of emphysema was expressed as a percentage of the area of the whole lung slice. This was ob:ained by dividing each slice into six equal parts using plastic rods and giving a maximal 'emphysema score' of 3 units to each part, i.e., maximum score of 18 units for each slice (Heard and Izukawa, 1964).

On the same lung slice the extent and type of emphysema were estimated by the point-counting method using a plastic grid (Dunnill, 1962; Hicken et 
al., 1966). The type of tissue under each point in the grid was noted and a count made of the numbers of the following components in each slice: panlobular emphysema (distensive and destructive), centrilobular emphysema (distensive and destructive), normal lung and non-parenchyma (blood vessels, bronchi, pleura, infarcts, etc.). The total of each component in the whole slice was obtained by addition and the extent of emphysema was expressed as a percentage $\left(\frac{\text { Emphysema }}{\text { Total score }} \times 100\right)$. The percentage of each type of emphysema was also calculated. Cases which showed more than $5 \%$ of each of the two main types (panlobular and centrilobular) were recorded as 'mixed'. Where less than $5 \%$ of the lung slice was involved by one type, then the predominant type of emphysema was noted.

In 46 of the 50 lungs a paper-mounted large section (Gough and Wentworth, 1960) was prepared from a lung slice adjacent to the one used for the other two methods. The severity of emphysema in the paper section was scored against a panel of standard charts (Thurlbeck et al., 1970). These charts are a series of $10 \times 8$ inch photographs of whole lung paper-mounted sections arranged in order of increasing severity of emphysema from $0-100$, at intervals of 5 between 0 and 50 and then at intervals of 10 from 60 to 100 . Each paper-mounted section prepared from the 46

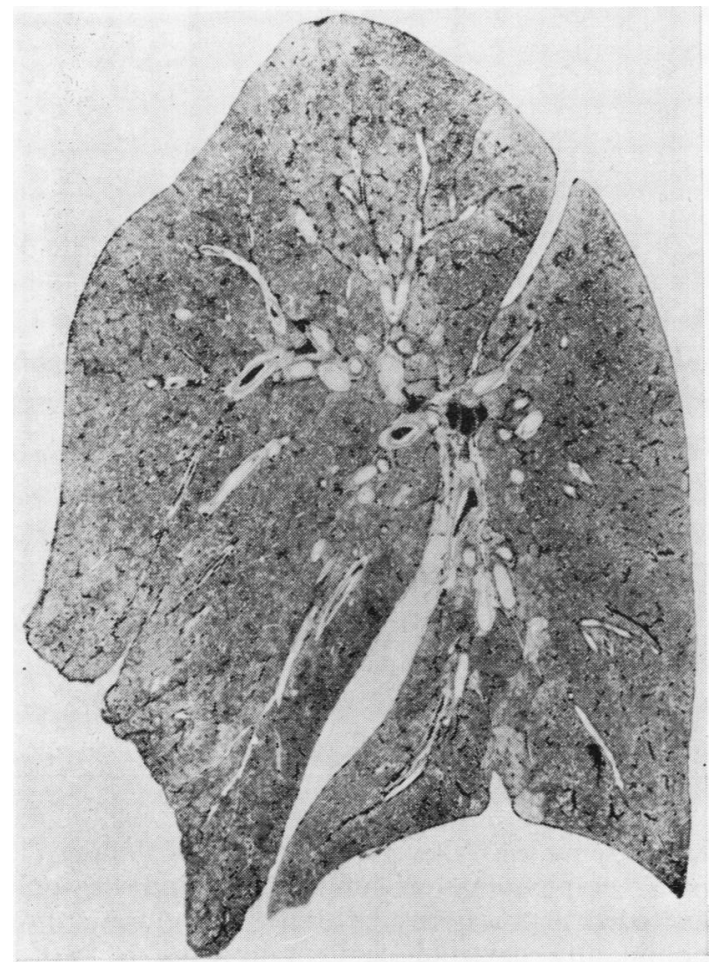

FIG. 1. Case 18. Standard chart score of $O$. lungs was compared with the standard charts and scored, without knowledge of the results using the other two methods (Figs 1-3 illustrate three cases from the

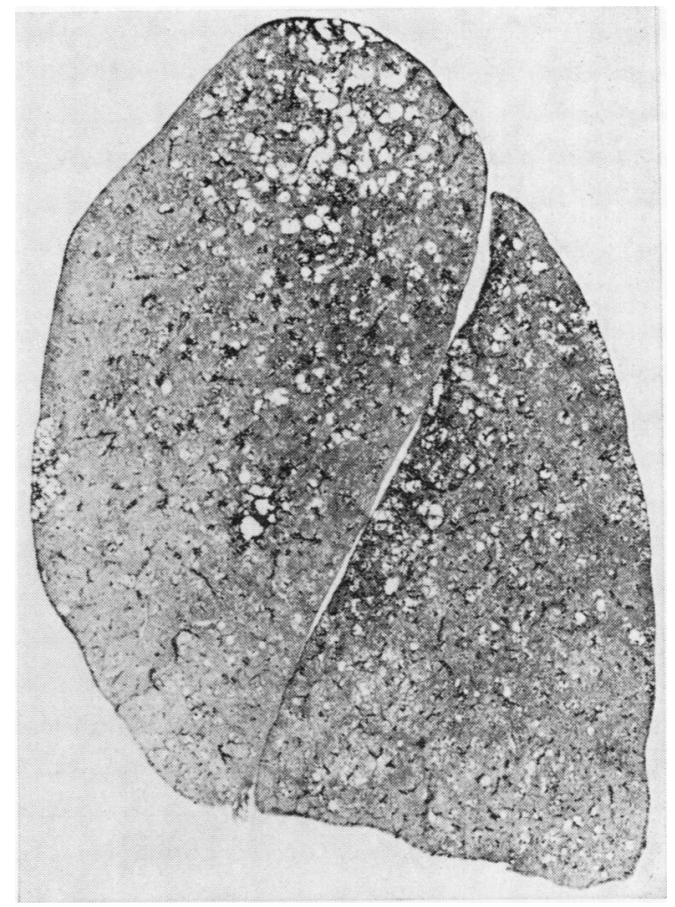

FIG. 2. Case 39. Standard chart score of 35.

series which have varying amounts of emphysema). This method represents arbitrary standards of emphysema according to severity; the figures obtained are not percentages of the lung area which are emphysematous.

The clinical notes of all patients were examined for evidence of chest disease.

\section{RESULTS}

INCIDENCE Of the 50 lungs examined, emphysema was present in $37(74 \%)$ (Table I). Calculating the 'Heard index' using the barium-impregnated slices ( $\left.\frac{\text { Units of emphysema }}{18} \times 100\right), 13$ lungs were completely free of emphysema and 5 showed only minimal amounts (less than 1 unit); 17 showed 1-3 units $(5-16 \%)$ and 11 showed $4-9$ units $(22-50 \%)$. In four cases more than $50 \%$ of the area of the lung slice was involved (over 10 units). The mean area of emphysematous lung in the 37 cases was $22 \%$ (Heard index) and $17 \%$ (point counting).

AGE As in other similar series dealing with necropsy material, most of the patients were middle 
aged or elderly. Only two were younger than 40 years; there was one patient in the tenth decade.

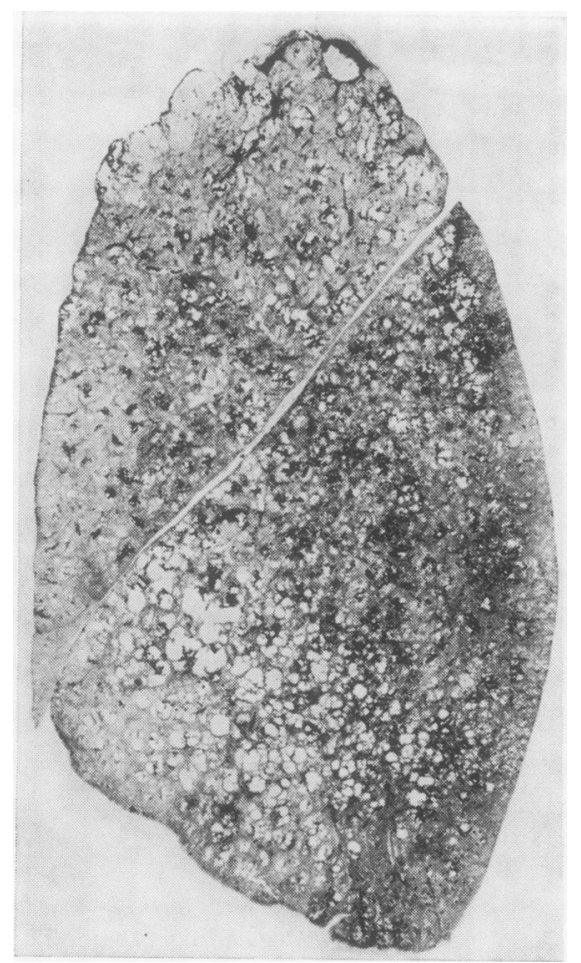

FIG. 3. Case 31. Standard chart score of 50.

Table II gives the mean areas of emphysematous lung for patients in each decade from the fifth to the ninth inclusive (Heard's method). The overall mean percentage area of emphysema was $20.0 \%$.

TYPE OF EMPHYSEMA Centrilobular emphysema was the commonest variety, as estimated by the point-counting method, and was present in 36 of the 37 emphysematous lungs (Table III). Pure centrilobular emphysema was present in 12 cases $(32 \%)$ and it was the predominant type in a further five cases $(13 \%)$, making a total of 17 cases $(46 \%)$. Centrilobular emphysema was mixed with panlobular emphysema in 15 cases (40\%) and was present in trace amounts in four cases (11\%).

Panlobular emphysema was present in 25 lungs. In only one case was pure panlobular emphysema found; it was the predominant type in another four lungs $(11 \%)$ and was mixed with centrilobular emphysema in 15 cases $(40 \%)$. It was present in trace amounts in a further five cases.
T A B L E I

INCIDENCE OF EMPHYSEMA IN 50 RANDOM LUNGS ESTIMATED BY THREE METHODS

\begin{tabular}{|c|c|c|c|c|c|}
\hline \multirow{2}{*}{$\begin{array}{l}\text { Case } \\
\text { No. }\end{array}$} & \multirow{2}{*}{ Age } & \multicolumn{2}{|c|}{ Heard's Method } & \multirow{2}{*}{$\begin{array}{c}\text { Point } \\
\text { Counting } \\
\%\end{array}$} & \multirow{2}{*}{$\begin{array}{c}\text { Standard } \\
\text { Charts }\end{array}$} \\
\hline & & Units & $\%$ & & \\
\hline 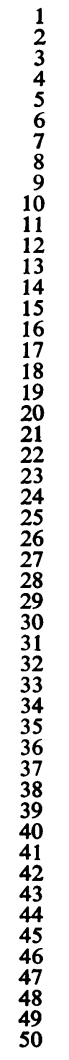 & 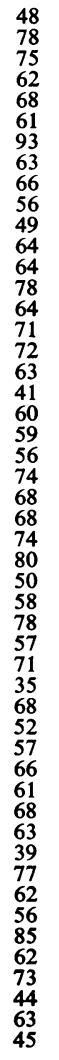 & 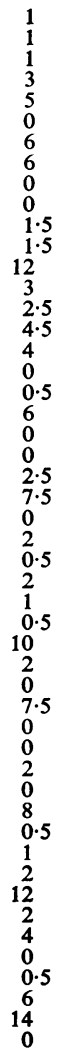 & $\begin{array}{r}6 \\
6 \\
6 \\
17 \\
28 \\
0 \\
33 \\
33 \\
0 \\
0 \\
8 \\
8 \\
67 \\
17 \\
14 \\
25 \\
22 \\
0 \\
3 \\
33 \\
0 \\
0 \\
14 \\
42 \\
0 \\
11 \\
3 \\
11 \\
6 \\
3 \\
55 \\
11 \\
0 \\
42 \\
0 \\
0 \\
11 \\
0 \\
45 \\
3 \\
6 \\
11 \\
67 \\
11 \\
22 \\
0 \\
3 \\
33 \\
78 \\
0\end{array}$ & $\begin{array}{r}7 \\
2 \\
4 \\
16 \\
22 \\
0 \\
25 \\
20 \\
0 \\
0 \\
7 \\
5 \\
53 \\
16 \\
15 \\
27 \\
18 \\
0 \\
4 \\
36 \\
0 \\
0 \\
17 \\
25 \\
0 \\
12 \\
5 \\
7 \\
4 \\
2 \\
34 \\
13 \\
0 \\
26 \\
0 \\
0 \\
5 \\
0 \\
25 \\
4 \\
33 \\
10 \\
64 \\
11 \\
19 \\
0 \\
4 \\
26 \\
46 \\
0\end{array}$ & $\begin{array}{r}5 \\
5 \\
0 \\
20 \\
25 \\
0 \\
35 \\
35 \\
0 \\
5 \\
55 \\
70 \\
15 \\
20 \\
25 \\
0 \\
55 \\
30 \\
0 \\
0 \\
10 \\
25 \\
20 \\
0 \\
5 \\
10 \\
5 \\
50 \\
15 \\
0 \\
25 \\
0 \\
0 \\
5 \\
0 \\
35 \\
0 \\
5 \\
10 \\
70 \\
5 \\
20 \\
10 \\
25 \\
70 \\
0\end{array}$ \\
\hline Mean & 63 & 2.9 & $16 \cdot 3 \%$ & $12.8 \%$ & $15 \cdot 4$ \\
\hline
\end{tabular}

T A B LE II

MEAN AREA OF EMPHYSEMATOUS LUNG IN FIFTH TO NINTH DECADES (HEARD'S METHOD)

\begin{tabular}{c|c|c|c}
\hline Age (yr) & $\begin{array}{c}\text { No. of } \\
\text { Patients }\end{array}$ & $\begin{array}{c}\text { No. with } \\
\text { Emphysema }\end{array}$ & $\begin{array}{c}\text { Mean } \\
\text { Area }\end{array}$ \\
\hline $40-49$ & 5 & 4 & $13 \%$ \\
$50-59$ & 9 & 4 & $21 \%$ \\
$60-69$ & 20 & 14 & $35 \%$ \\
$70-79$ & 11 & 10 & $18 \%$ \\
$80-89$ & 2 & 2 & $13 \%$ \\
\hline
\end{tabular}

A mixed pattern of centrilobular and panlobular emphysema was therefore a common finding (15 of 37 emphysematous lungs, $40 \%$ ) and was only exceeded in frequency by lungs with pure or predominantly centrilobular emphysema, of which there were 17 (46\%). 


\section{T A B L E I I I}

TYPE OF EMPHYSEMA IN 37 LUNGS (POINT-COUNTING METHOD)

\begin{tabular}{l|rrr|c|c}
\hline $\begin{array}{c}\text { Type of } \\
\text { Emphysema }\end{array}$ & \multicolumn{3}{|c|}{$\begin{array}{c}\text { No. of Cases } \\
\text { Pre- } \\
\text { dominant (Trace) }\end{array}$} & $\begin{array}{c}\text { No. of } \\
\text { Distensive }\end{array}$ & $\begin{array}{c}\text { No. of } \\
\text { Distensive } \\
\text { and } \\
\text { Destructive }\end{array}$ \\
\hline $\begin{array}{l}\text { Centrilobular } \\
\text { Panlobular } \\
\text { Mixed }\end{array}$ & 12 & 5 & (4) & 10 & 7 \\
\hline
\end{tabular}

Each type of emphysema was divided into distensive and destructive varieties (Table III). Sixteen lungs $(43 \%)$ showed only distensive emphysema. The commonest type was centrilobular distensive, present in 10 of the 37 emphysematous lungs $(27 \%)$. Distensive panlobular emphysema was the predominant type in two lungs and a mixed pattern of panlobular and centrilobular distensive emphysema was found in four lungs.

Destructive emphysema was always found in association with distensive emphysema of the same type. There were 21 cases (57\%) showing distensive and destructive changes; in 11 of these there was mixed panlobular and centrilobular emphysema. Destructive centrilobular and panlobular emphysema were slightly less common on their own (seven and three cases respectively).

COMPARISON OF METHODS In 30 of the 37 emphysematous lungs, the percentage difference in emphysema using the 'Heard index' and the pointcounting method was within $1-9 \%$. In the remaining seven lungs the percentage of emphysematous lung using Heard's method was from 13 to $32 \%$ higher than the value obtained by the point-counting method (cases $8,13,24,31,34,39,49$ ). In four of these the emphysema was predominantly destructive.

The results with the standard charts were compared with the results using Heard's method with the barium-impregnated lung slices. Emphysema in the standard charts was divided into mild (5-20), moderate (31-50), and severe (over 50) (Table IV).

\section{T A B L E I V}

COMPARISON OF HEARD'S METHOD AND THE STANDARD CHARTS

\begin{tabular}{|c|c|c|c|}
\hline $\begin{array}{l}\text { Severity of } \\
\text { Emphysema }\end{array}$ & $\begin{array}{l}\text { No. of } \\
\text { Cases }\end{array}$ & $\begin{array}{c}\text { Standard } \\
\text { Charts }\end{array}$ & $\begin{array}{l}\text { Heard's } \\
\text { Method }\end{array}$ \\
\hline $\begin{array}{l}\text { Mild } \\
\text { Moderate } \\
\text { Severe }\end{array}$ & $\begin{array}{r}20 \\
10 \\
3\end{array}$ & $\begin{array}{r}5-20 \\
21-50 \\
+50\end{array}$ & $\begin{array}{r}5-25 \% \\
22-55 \% \\
67-78 \%\end{array}$ \\
\hline
\end{tabular}

With a standard chart score of 5-20, no more than one-quarter of the lung slice was emphy- sematous with Heard's method. In severe emphysema with a score greater than 50 , at least twothirds of the lung slice showed emphysema. With a moderate degree of severity (21-50), about onequarter to one-half of the lung slice was emphysematous.

\section{DISCUSSION}

Glasgow and the west of Scotland have a high incidence of clinical chronic bronchitis and emphysema and also a high death rate from these diseases.

The present study from a series of necropsies on male subjects in Glasgow revealed emphysema in $74 \%$ of the 50 lungs examined. Disregarding trace amounts (less than 1 unit), emphysema was present in 32 lungs (64\%). Emphysema in more than trace amounts has been reported in $74 \%$ of 50 consecutive necropsies on male subjects in London (Heard and Izukawa, 1964) and in $73 \%$ of 47 necropsies in Edinburgh (Heard and Hossain, 1970). This difference between Glasgow on the one hand and London and Edinburgh on the other is not statistically significant $(\mathrm{P}>0.50)$. Gough et al. (1967) found emphysema in $61.8 \%$ of men aged 60-89 years in Cardiff. In the present series there were 33 patients in this age group and 22 of them $(67 \%)$ had more than trace amounts of emphysema. There does not therefore appear to be a significant difference in the incidence of emphysema in males in different urban centres of the United Kingdom.

The mean area of emphysema in males in the fifth to the ninth decades was $20.0 \%$ in Glasgow, $21.9 \%$ in London, and $20.3 \%$ in Edinburgh (Heard and Izukawa, 1964; Heard and Hossain, 1970). The present series is not large enough for definite conclusions to be made as to the incidence of emphysema at different ages. The results, however, do suggest that emphysema in Glasgow is more severe than in London or Edinburgh among younger men. In the fifth decade the mean area of emphysematous lung was $13 \%$ in Glasgow, $3.0 \%$ in London, and $5.4 \%$ in Edinburgh. In the sixth decade the mean area of emphysematous lung was higher in Glasgow and London than in Edinburgh (21\%, $24 \%$, and $9.5 \%$ respectively).

In Glasgow centrilobular emphysema was the commonest variety and was present in 36 of the 50 lungs $(72 \%)$; it was the predominant or only type present in 17 cases (34\%). This is very similar to the results of Heard and Hossain (1970) in Edinburgh, where centrilobular emphysema was the predominant type in 19 of 47 lungs (40\%). The predominance of each type of emphysema was not 
recorded in the London series (Heard and Izukawa, 1964). In Cardiff (Gough et al., 1967) centrilobular emphysema was the predominant or only type present in 65 of 171 emphysematous lungs from male patients $(38 \%)$, as compared to 17 of 37 emphysematous lungs in Glasgow (46\%).

Panlobular emphysema was found in 25 of the 50 lungs in Glasgow (50\%) and was the predominant or only type in $5(10 \%)$. In Edinburgh panlobular emphysema was found in 27 of 47 lungs $(52 \%)$ and it was the predominant or only type in $8(17 \%)$ (Heard and Hossain, 1970). In Cardiff panlobular emphysema was the only or predominant type in 69 of 171 emphysematous male lungs (31\%) (Gough et al., 1967). In London, panlobular emphysema was commoner and found in 40 of 50 lungs $(80 \%)$ (Heard and Izukawa, 1964). It was the destructive panlobular emphysema which was in excess in London and found in 39 of 50 lungs $(78 \%)$, compared to 17 of 50 lungs in Glasgow (34\%) and 23 of 47 in Edinburgh (48\%).

A mixed pattern of centrilobular and panlobular emphysema was common in Glasgow and found in 15 lungs $(30 \%)$. This is considerably more than the five showing pure or predominant panlobular emphysema and close to the 17 lungs which showed pure and predominant centrilobular emphysema. In Cardiff (Gough et al., 1967) a mixed pattern of panlobular with centrilobular emphysema was found in 49 of 171 male emphysematous lungs $(29 \%)$; in Glasgow $40 \%$ of the 37 emphysematous lungs showed a mixed pattern.

In Glasgow, therefore, the centrilobular and mixed varieties of emphysema are commoner than the pure or predominant panlobular emphysema. In this respect Glasgow is similar to Edinburgh and different from London.

In this study emphysema has been measured by three methods, but these are not strictly comparable. Heard and Izukawa's method (1964) measures the percentage area of emphysematous lung in the barium-impregnated slice. It is also a measure of severity, for distensive emphysema of whatever extent is given only a maximum score of $\frac{1}{2}$ out of 3 for each of the six subdivisions of the lung slice. The method is therefore weighted in favour of destructive emphysema.

The point-counting method is the only true quantitative method and measures the extent but not necessarily the severity of emphysema (Thurlbeck et al., 1970). This method tends to give low scores with centrilobular emphysema and to produce large scores with panlobular emphysema.

Thurlbeck and his colleagues (1970) are of the opinion that the comparison of paper-mounted large sections with the standard charts enables the pathologist to make an 'acceptable estimate' of the severity of emphysema and that the method is of value both in routine diagnostic work and in epidemiological surveys. These standard charts measure the severity of emphysema on an arbitrarily devised scoring system but the different types of emphysema are not differentiated. Thurlbeck et al. (1970) stress that it is, therefore, incorrect to use this method for clinicopathological correlation. Unlike the other two methods used in the present study, the score is not a percentage of the area of the lung section which is emphysematous.

Direct comparison of the results using the standard charts and the 'Heard index' with the 을 barium-impregnated lung slices is therefore difficult. Our results, however, do suggest a broad correlation (Tab'e IV). We have found that the method of scoring is quick and the paper-mounted large sections (Gough and Wentworth, 1960) give a permanent, easily stored record. The storage of barium-impregnated slices presents more problems, particularly in hospital laboratories where storage space is often at a premium.

We are grateful to Professor Jethro Gough for helpful comments and criticism of the manuscript.

\section{REFERENCES}

Dunnill, M. S. (1962). Quantitative methods in the study of pulmonary pathology. Thorax, 17, 320 .

Gough, J., Ryder, R. C., Otto, H., and Heller, G. (1967). Vergleichende morphologische Untersuchungen zur Haufigkeit des Lungenemphysems. Frankfurt Z. Path. 77, 317.

and Wentworth, J. E. (1960). Thin sections of entire organs mounted on paper. In Recent Advances in Pathology, edited by C. V. Harrison, 7th ed., p. 80. J. and A. Churchill, London.

Heard, B. E. (1958). A pathological study of emphysema of the lungs with chronic bronchitis. Thorax, 13, 136.

(1969). Pathology of Chronic Bronchitis and Emphysema, p. 46. J. and A. Churchill, London.

and Hossain, S. (1970). Emphysema in Edinburgh. Path. Microbiol., 35, 167.

and Izukawa, T. (1964). Pulmonary emphysema in $\mathrm{N}$ fifty consecutive male necropsies in London. J. Path. Bact., 88, 423.

Hicken, P., Heath, D., and Brewer, D. (1966). The relation between the weight of the right ventricle and the percentage of abnormal air space in the lung in emphysema. J. Path. Bact., 92, 519.

Report of the Medical Officer of Health, City of Glasgow (1969).

Thurlbeck, W. M., Dunnill, M. S., Hartung, W., Heard, B. E., Heppleston, A. G., and Ryder, R. C. (1970). A comparison of three methods of measuring emphysema. Human Pathology, 1, 215. 